\title{
INOVAÇÃO PARA O DESENVOLVIMENTO SUSTENTÁVEL COMO FATOR DE COMPETITIVIDADE PARA AS ORGANIZAÇÕES: UM ESTUDO DE CASO DURATEX
}

\author{
Marta Fabiano Sambiase \\ Doutora em Administração de Empresas pela Universidade Presbiteriana Mackenzie - MACKENZIE \\ Professor Assistente Dr. da Universidade Presbiteriana Mackenzie - MACKENZIE \\ martafsambiase@gmail.com (Brasil)
}

\section{Marcos Antonio Franklin}

Doutor em Administração de Empresas pela Universidade Presbiteriana Mackenzie - MACKENZIE Professor Assistente Dr. da Universidade Presbiteriana Mackenzie - MACKENZIE franklin.marcos@gmail.com (Brasil)

\section{Jaqueline Alfim Teixeira}

Bacharel em Administração de Empresas pela Universidade Presbiteriana Mackenzie - MACKENZIE jaquelinealfim@gmail.com (Brasil)

\section{RESUMO}

Este artigo tem por objetivo pesquisar a relação existente entre desenvolvimento sustentável e competitividade das organizações, a fim de identificar se as inovações empresariais orientadas pelas políticas de sustentabilidade organizacional influenciam na competitividade da Duratex; empresa fabricante de produtos de madeira, louças e metais sanitários, destinados à indústria de móveis e à construção civil. Este trabalho é composto por parte teórica para esclarecer conceitos relacionados à competitividade das organizações, desenvolvimento sustentável e inovação empresarial, bem como as relações existentes entre eles. A pesquisa realizada foi de natureza exploratória, abordagem qualitativa por meio da estratégia do estudo de caso da Duratex com técnicas de levantamento de dados documentais, secundários, observação e entrevistas semiestruturadas. As análises das entrevistas foram realizadas segundo técnica de análise de conteúdo e apontam para resultados que demonstram que a Duratex inseriu a sustentabilidade em sua gestão estratégica e operacional, tendo lançado mão de inovações de produtos e processos em busca de maior equilíbrio entre o social, ecológico e econômico, em práticas distribuídas por sua cadeia produtiva. Dessa forma, as inovações listadas são orientadas à sustentabilidade e os resultados de desempenho empresarial indicam que, não só as inovações, mas a gestão orientada à sustentabilidade da Duratex contribui para sua competitividade.

Palavras-chave: Inovação; Sustentabilidade; Desenvolvimento Sustentável; Competitividade. 


\section{INTRODUÇÃO}

O estudo sobre a competitividade das organizações é um tema relevante para a administração de empresas porque os gestores, diretamente ou indiretamente, influenciam sobre ela por meio de decisões e práticas adotadas no dia a dia das empresas (Brito \& Vasconcelos, 2004).

Tentativas de estabelecimento de modelos capazes de explicar causas e efeitos dos movimentos dos mercados e empresas são apresentadas com o intuito de garantir sobrevivência e longevidade das organizações e nações, bem como da qualidade de vida aos habitantes e preservação ecológica. É neste cenário que se encaixa a adoção de políticas voltadas ao desenvolvimento sustentável, como forma de integração de questões econômicas, sociais e ecológicas.

Sambiase-Lombardi e Brito (2007) discutem a ideia que Desenvolvimento Sustentável (DS) pode ser fator de competitividade da firma por meio de dimensões determinadas pelos valores humanos, inovação e capital social, fundamentalmente. Competitividade da firma é vista como a capacidade desta em formular e implantar estratégias concorrências, que lhe permitam ampliar ou conservar, de forma duradoura, uma posição sustentável no mercado, que só é possível diante de um ambiente natural e social sustentável (Ferraz, Kupfer \& Haguenauer, 1996). O conceito de DS foi concebido em esfera macroambiental e para que seja fator de competitividade da firma, os autores apresentam uma proposta de transposição deste conceito para o nível da firma. A contribuição desta proposição está em elaborar um nivelamento dos conceitos de DS e competitividade, chegando a um modelo para a realização de estudos empíricos em organizações.

A partir da discussão da relação existente entre Desenvolvimento Sustentável e Competitividade das Organizações (Sambiase-Lombardi \& Brito, 2007), este artigo tem como objetivo, identificar se as inovações empresariais orientadas pelas políticas de desenvolvimento sustentável influenciam na competitividade da Duratex, tornando-se, assim, fator de competitividade.

Sbragia, Stal, Campanário e Andreassi (2006) defendem a contribuição e o papel da inovação tecnológica para o desenvolvimento das firmas e do ambiente socioeconômico dos países, é por meio da criação de novas oportunidades de negócios, que deixam claras as ligações entre competitividade e empresas e, até mesmo, entre países. Num contexto macroambiental, o desenvolvimento sustentável tem sido usado por muitos grupos e de diversas maneiras, onde o mais usado é o do relatório Brundtland (1987), onde é tido como o processo de mudanças onde a exploração de recursos, direção

Revista de Administração e Inovação, São Paulo, v. 10, n.2, p. 144-168, abr./jun. 2013. 
dos investimentos, orientação do desenvolvimento tecnológico e alterações institucionais, são realizadas de maneira consistente com as necessidades atuais e futuras.

Senge, Carstedt e Porter (2001) argumentam que a indústria está diante de uma encruzilhada; o impacto de novas práticas de produção e a disponibilidade de recursos pode acarretar em uma nova revolução industrial. A extraordinária criatividade de equipes tem sua origem no reconhecimento de restrições - como a restrição da natureza.

Este estudo realizou um estudo de caso na Duratex - empresa brasileira do setor madeireiro, cuja extensão da cadeia produtiva torna o trabalho rico e abrangente. A Duratex se ocupa do cultivo de mudas e florestas, passando pelo processo industrial, definição e oferta de produtos para o consumidor final, que o faz por meio da comercialização de produtos de decoração e acabamentos para a construção civil, principalmente. Os objetivos específicos deste estudo são definidos: (1) levantar as inovações realizadas pela empresa Duratex, tanto em termos de produtos como processos; (2) identificar se estas inovações são orientadas por políticas sustentáveis; e (3) investigar se estas inovações influenciam na competitividade da Duratex, proporcionando-lhe desempenho favorável.

Os resultados apontam que a Duratex sempre se empenhou em adaptar seus produtos e processos às condições impostas pelo mercado de vanguarda, tais como, a preocupação com o meio ambiente, atendimento das mais exigentes leis ambientais (nacionais e internacionais), e percepção do consumidor ao que tange a ações sociais e sustentáveis.

\section{REFERENCIAL TEÓRICO}

Essa seção está destinada a apresentação da fundamentação teórica, partindo do conceito macroambiental de desenvolvimento sustentável para, então, relacionar competitividade das organizações em nível microambiental e inovação em nível de firma.

\subsection{Desenvolvimento Sustentável}

De acordo com o levantamento realizado na literatura acadêmica, governamental e não acadêmica, identificou-se que existem muitas maneiras diferentes onde o termo desenvolvimento sustentável tem sido aplicado e definido. O termo surgiu em esfera da economia macroambiental, transmitindo preocupações e desafios das nações, governos e instituições relacionadas a estes. Romeiro

Revista de Administração e Inovação, São Paulo, v. 10, n.2, p.144-168, abr./jun. 2013. 
(2001, p. 7-8) defende que o progresso científico e tecnológico é visto como fundamental para aumentar a eficiência na utilização dos recursos naturais em geral (renováveis e não renováveis). Permanece, entretanto, a discordância fundamental em relação à capacidade de superação indefinida dos limites ambientais globais. Em longo prazo, a sustentabilidade do sistema econômico não é possível sem estabilização dos níveis de consumo per capita de acordo com a capacidade de carga do planeta.

O conceito de desenvolvimento sustentável é usado em diversas situações; no Brasil, institutos (Ethos, 2007), associações (ABIDES, 2011) e fundações (FBDS, 2011), escolas como Centro de Estudos de Sustentabilidade Fundação Getúlio Vargas (GVCES, 2007) e mercados (BOVESPA, 2007) disseminam práticas e apoiam projetos relacionados à operacionalização do tema. Fora do Brasil, há casos de Instituições de Ensino que estabelecem acordos de cooperação com instituições de iniciativa governamental ou não. Dentre estes casos, há o CLACDS - Centro Latino-Americano para Competitividade e Desenvolvimento Sustentável (CLACDS, 2007); ele foi fundado em 1995, após um trabalho intenso realizado por Michael Porter, da Harvard Business School, onde também participa Dr. Jeffrey Sachs, economista de renome mundial e outros acadêmicos. Brizio Biondi-Morra, então Reitor do Incae Business School, e Stephan Schmidheiny, na época Presidente da Avina (2011), demonstraram também preocupação com a competitividade das nações ou blocos econômicos com o desenvolvimento sustentável macroeconômico Incae (2011).

Do ponto de vista organizacional, Schaltegger e Wagner (2008) já destacavam o crescimento de forma visível na gestão das empresas, por parte dos líderes, nas questões fundamentais do desenvolvimento sustentável. Para esses autores, com as inovações, empresários e gestores estão moldando os mercados, e consequentemente à sociedade, proporcionando melhorias organizacionais, bem como técnicas que podem ser vendidas no mercado com muito sucesso, uma vez, que as inovações exigem objetivos ambientais e sociais que podem ser bem sucedidos em mercados com clientes tracionais. Nesse sentido, "atores e empresas percebendo o sucesso no mercado de massa, e garantir ao mesmo tempo, o progresso ambiental e social em seu core business, podem ser chamados de "empreendedores sustentáveis" [tradução nossa] (Schaltegger \& Wagner, 2008, p. 28)". Assim, esses atores e empresas, por meio de novos produtos, serviços, técnicas e formas organizacionais, podem reduzir consideravelmente os impactos ambienteis e sociais aumentando a qualidade de vida.

Revista de Administração e Inovação, São Paulo, v. 10, n.2, p. 144-168, abr./jun. 2013. 


\subsection{Competitividade das Organizações}

A competitividade, em termos teóricos, tem sido discutida por autores como (Ferraz, Kupfer \& Haguenauer, 1996). Uma forma bastante apropriada é apresentada por Hughes (1987) apud SambiaseLombardi e Brito (2007), onde o autor analisa competição como um processo dinâmico relacionando mudanças estruturais com o comportamento do mercado. A competição é definida, no mundo dos negócios, como um processo que envolve rivalidade entre organizações; esta envolve tanto os contextos dos mercados, como o potencial para inserção em novas áreas onde o retorno é aparentemente atrativo.

A competição pode ser vista como um processo dinâmico, onde uma política de competição deve considerar condições econômicas existentes e comportamentos de mercado e empresas. Schumpeter (1961) considera que o capitalismo é evolutivo, definindo como fato essencial o processo de destruição criativa, que segundo o autor, se dá pelo surgimento de novas estruturas em função da consequente destruição das anteriores.

Kupfer (1992, p. 4) desenvolve uma "definição de competitividade como sendo a adequação das estratégias adotadas pela firma em relação ao padrão de concorrência vigente na(s) indústria(s) considerada(s)". Portanto, para este estudo, competitividade organizacional será tratada como "a capacidade da empresa formular e implementar estratégias concorrências, que lhe permitam ampliar ou conservar, de forma duradoura, uma posição sustentável no mercado"; complementando "é, portanto, no processo de decisão das estratégias empresariais que se deve buscar os elementos analíticos centrais de compreensão da competitividade” (Ferraz, Kupfer \& Haguenauer, 1996, p. 5).

Os padrões de concorrência são munidos de dois aspectos fundamentais para avaliação da competitividade: (1) a natureza específica de cada setor e (2) o fato de serem mutáveis no tempo. Isto nos esclarece que a competitividade não é uma questão intrínseca a um produto, firma ou país; ela é um fenômeno que se forma no âmbito da indústria, no conjunto de firmas que a constitui, e no mercado.

As análises de competitividade devem levar em conta os processos internos à empresa, ao setor e as condições econômicas gerais do ambiente. Diante disto, este estudo sente-se instigado a compreender se a busca por processos e produtos inovadores realizada pelas empresas, compatíveis com políticas de sustentabilidade, é uma questão impulsionada pela concorrência, pelo risco de escassez de recursos ou pela exigência dos consumidores.

Revista de Administração e Inovação, São Paulo, v. 10, n.2, p.144-168, abr./jun. 2013. 


\subsection{Inovação}

O conceito de inovação é bastante variado, dependendo, principalmente, da sua aplicação. De forma sucinta, inovação é a exploração com sucesso de novas ideias. E sucesso para as empresas pode significar aumento de faturamento, acesso a novos mercados, aumento das margens de lucro, entre outros. Schumpeter (1961) explica o desenvolvimento econômico por meio de sua teoria de "destruição criadora", onde com ela o consumidor muda o seu hábito de compra, ou seja, produtos ou hábitos antigos são substituídos pelos reinventados. Assim, Schaltegger e Wagner (2008) entendem que os empreendedores sustentáveis devam destruir os métodos de produção, assim como, produtos, serviços e padrões de consumo convencionais, criando-os e substituindo-os por novas possibilidades como, produtos com níveis de qualidade ambientais e sociais altos. Dessa maneira, "criam a dinâmica do mercado de progresso sustentável (Schaltegger \& Wagner, 2008, p. 28)”.

Há tempos que a questão da inovação tecnológica vem despertando a atenção de estudiosos do tema (Sbragia et al., 2006). Já no século XVIII Adam Smith apontava a relação entra acumulação de capital e tecnologia de manufatura, estudando conceitos relacionados à mudança tecnológica, divisão de trabalho, crescimento da produção e competição. Portanto, foi só a partir dos trabalhos de Shumpeter, que a tecnologia é analisada mais a fundo nas respectivas teorias de desenvolvimento econômico.

Shumpeter (1961) menciona cinco tipos de inovação, que são: (1) introdução de um novo bem; (2) introdução de um novo método de produção, ou seja, um método ainda não testado e que tenha sido gerado a partir de uma nova descoberta científica; (3) abertura de um novo mercado, ou seja, um mercado em que uma área específica da indústria ainda não tenha penetrado; (4) a conquista de uma nova fonte de suprimento de matéria-prima; e (5) o aparecimento de uma nova estrutura de organização em um setor.

Dentre as várias possibilidades de inovar, aquelas que se referem às inovações de produto ou de processo são conhecidas como inovações tecnológicas. Outros tipos de inovações podem se relacionar a novos mercados, novos modelos de negócios, novos processos e métodos organizacionais, ou até mesmo novos fontes de suprimentos, proporcionando um crescimento sustentável ao longo do tempo.

Para Dosi (2006), a inovação, essencialmente, está relacionada à descoberta, experimentação, desenvolvimento, imitação e adoção de novos produtos, novos processos de produção e novos arranjos organizacionais. Por sua vez, a mudança técnica é, em geral, uma das forças motoras fundamentais do 
crescimento econômico e da transformação estrutural das sociedades modernas. A inovação tem a capacidade de agregar valor aos produtos de uma empresa, diferenciando-a, ainda que momentaneamente, no ambiente competitivo. As inovações são importantes porque elas permitem que as empresas acessem novos conhecimentos, novos mercados, aumentem suas receitas, realizem novas parcerias e aumentem o valor de suas marcas. Sob a perspectiva da sustentabilidade, Schaltegger e Wagner (2008) entendem que, as empresas que tratam as questões relacionadas à sustentabilidade como parte fundamental em suas atividades centrais ligadas ao seu core business, não obstante, seu segmento ou setor da economia, porém não focando no mercado de massa, mas sim, em nichos de mercado, segundo os esses autores, é provável que seja uma inovação sustentável, entretanto em nicho.

As empresas são o centro da inovação; é por meio delas que as tecnologias, invenções, produtos, enfim, ideias, chegam ao mercado. As empresas devem entender o que é inovação e qual a sua dinâmica. A partir daí elas podem definir uma estratégia em relação à inovação que deve estar alinhada com a estratégia geral da empresa e com a sua visão de futuro. A atenção para o futuro é uma premissa para a empresa inovar (Sbragia et al., 2006).

Outro ponto apresentado por Tidd, Bessant e Pavitt (2008) quanto a produtos novos se trata da capacidade de desenvolvimento dos mesmos, pois o meio ambiente está constantemente em mudança. As alternâncias socioeconômicas (naquilo em que as pessoas acreditam, esperam, querem e ganham) criam oportunidades e restrições. A legislação pode abrir novos campos, mas podem fechar outros: como, aumentar as exigências para produtos ecologicamente orientados. Os concorrentes podem introduzir novos produtos que representem ameaças as posições de mercado existentes. Em todos os casos citados, as empresas precisam estar preparadas para reagir por meio da inserção de novos produtos.

Segundo Tidd et al. (2008) existem quatro tipos de inovação são eles: (i) Inovação de Produto Mudanças nas coisas (produtos/serviços), que uma empresa oferece. (ii) Inovação de Processo Mudanças nas formas em que os produtos/serviços são criados e entregues. (iii) Inovação de Posição Mudanças no contexto em que produtos/ serviços são introduzidos. (iv) Inovação de Paradigma Mudanças nos modelos mentais subjacentes que orientam o que a empresa faz. Para esses autores configuram-se os " 4 Ps" da inovação.

\subsection{Inovação, Competitividade e Desenvolvimento Sustentável}

A competitividade também pode ser vista como potencial competitivo, traduzidos em termos da 
relação insumo-produto ou sua capacidade de converter insumos em produtos com o máximo rendimento. É o produtor que define sua competitividade ao escolher as técnicas que utiliza. Como fonte de competitividade pode-se considerar o domínio de técnicas mais produtivas que interfere na competição de sucesso da empresa (Haguenauer, 1989; Kupfer, 1992; Ferraz, Kupfer \& Haguenauer, 1996).

O domínio de técnicas vem a ser um desafio para os negócios no sentido de desenvolver estratégias de inovação que correspondam ao aumento de pressões ambientais e sociais, e ainda considerem as necessidades e expectativas de vários stakeholders (Senge \& Carstedt, 2001). Alguns estudos têm tratado da integração entre processos de inovação organizacional a partir do ponto de vista do desenvolvimento sustentável (Ayuso et al., 2006; Bossink, 2007; Senge \& Carstedt, 2001). Ayuso et al. (2006) são taxativos ao afirmar que "desenvolvimento sustentável não acontecerá sem inovação".

E ao mesmo tempo em que o desenvolvimento sustentável fornece oportunidade de crescimento e aumento de competitividade, sua filosofia pode ser uma fonte de inspiração para prover inovação (Hall \& Vredenburg, 2003; Hart \& Milstein, 1999).

Senge e Carstedt (2001) chamam de "próxima revolução industrial" ao processo de inovação das organizações para garantir sobrevivência nos próximos tempos; foi o que Schumpeter chamou de destruição criativa, onde velhas indústrias morrem e novas nascem, onde ondas de tecnologia disruptiva aceleram e expandem a Revolução Industrial.

Movimentos de diversas empresas são relatados pelo Centro de Estudos Brasileiros para o Desenvolvimento Sustentável (CEBDS, 2007). A empresa alemã Basf, que atua nos cinco continentes e fatura mais de US\$ 45 bilhões por ano, exercita sua visão de sustentabilidade por meio do EcoEfficiency Analysis. Trata-se de um processo destinado a analisar e aperfeiçoar o uso de matériasprimas e energia em seus processos produtivos, bem como monitorar o impacto de atividades da empresa na água e na atmosfera.

Encontra-se um compromisso similar na General Electric, empresa que fatura US\$ 150 bilhões por ano atuando em setores tão diferentes como automotivo, aviação, equipamentos médicos e finanças, entre outros. Seu programa EcoImagination se traduz no compromisso de criar produtos e serviços cada vez mais inovadores, eficientes e ambientalmente corretos (CEBDS, 2007). Empresa com mais de 200 anos de existência, a DuPont se impôs o compromisso de manter uma política de inovação que privilegia a criação de produtos capazes de atuar em linha com desafios de segurança, meio ambiente, energia e clima. A DuPont opera em mais de 70 países, tem vendas anuais na casa dos US\$ 27 bilhões e criou um programa chamado Metas de Sustentabilidade 2015. Ele prevê ações Revista de Administração e Inovação, São Paulo, v. 10, n.2, p. 144-168, abr./jun. 2013. 
concretas para todas as áreas da companhia, do marketing às atividades de pesquisa e desenvolvimento, até aquele ano (CEBDS, 2007).

\section{MÉTODO DE PESQUISA}

Este estudo, de natureza exploratória de acordo com Cervo e Bervian (2006), foi realizado por meio do método qualitativo (Creswell, 1998; Bryman, 2004; Godoy, 2006), com estratégia do estudo de caso (Eisenhardt, 1989; Yin, 2003) da empresa Duratex, cuja unidade de referencia para análise envolveu toda a empresa, pois as inovações de processos, fundamentalmente, permeiam por toda a organização.

Foram utilizados dados secundários para um primeiro levantamento, onde foram analisados Balanços de Sustentabilidade da empresa, principalmente. Foram realizadas visitas à Duratex, na unidade administrativa de São Paulo e a na unidade florestal e fabril em Agudos, interior do Estado de São Paulo. Assim, a coleta de dados se deu através de técnicas de observação e entrevistas pessoais, além de extenso levantamento de dados secundários, em relatórios de sustentabilidade e de resultados financeiros, assim como no site da empresa e mídia pública (Duratex, 2008; 2011). O instrumento de coleta dos dados se baseou em um roteiro semiestruturado, elaborado a partir da revisão da literatura para conceituação das variáveis em estudo e suas relações, que serviu como orientador às entrevistas.

Foram realizadas três entrevistas com os seguintes funcionários: Sr. José - Gerente de Sustentabilidade da Duratex; Sra. Angélica, supervisora técnica da Durafloor - área florestal da empresa; e Sra. Priscila, da área de controle de qualidade industrial. As entrevistas foram gravadas e transcritas, e em seguida foi realizada análise de dados segundo instruções de Flores (1994). Os resultados da análise das entrevistas estão disponíveis no decorrer da apresentação do estudo de caso e conclusões.

\section{ESTUDO DE CASO: DURATEX}

A Duratex é uma empresa privada nacional de capital aberto, com ações negociadas na Bolsa de Valores de São Paulo desde 1951. Ela é controlada pelo Grupo Itaúsa - Investimento Itaú S.A., do

Revista de Administração e Inovação, São Paulo, v. 10, n.2, p.144-168, abr./jun. 2013. 
qual também fazem parte o Banco Itaú Holding Financeira S.A., a Elekeiroz S.A., a Itautec S.A. e a Itaúsa Empreendimentos (Duratex, 2008, 2010, 2011).

A Duratex tem nove unidades industriais: sete no Estado de São Paulo, uma no Rio Grande do Sul e outra na Argentina, onde a subsidiária Deca Piazza produz metais sanitários. A Duratex é organizada em duas divisões: Madeira e Deca, responsáveis, respectivamente, por cerca de 70\% e 30\% do volume total de vendas. A empresa é líder no mercado brasileiro de produção de painéis de madeira reconstituída e pisos laminados, este, comercializado sob a marca Durafloor, com posição destacada no mercado.

\section{ANÁLISES E RESULTADOS}

\subsection{A Duratex e a Sustentabilidade}

Em entrevista com Sr. José, gerente de sustentabilidade da Duratex, foi esclarecido que a sustentabilidade chegou à organização por meio de iniciativas do presidente, Sr. Paulo Setúbal, com o intuito de atender às mais exigentes legislações e tratar o tema de forma estratégica para a empresa. $\mathrm{Na}$ entrevista, foi possível identificar mais dois fatores fundamentais de estimulo inicial à adoção de políticas orientadas ao desenvolvimento sustentável: atender as exigências do mercado internacional, fator claramente identificado na afirmação do entrevistado:

"A Duratex na década de 1990 já tinha o processo de FSC implantado e ISO 14.000. O 14.000 surgiu em 1996. Nós já tínhamos todo o processo de implementação antes mesmo da ISO ter formalizado a primeira versão da 14.000. Então quando saiu a primeira versão em 1996, foi muito rápida a certificação. O FSC chegou, seguiu a mesma linha. Preocupado com o quê? Com barreiras não tarifárias para o mercado internacional. No mercado nacional, nós não temos ainda esse nível de consciência de consumidor, de: "-Eu vou pagar $10 \%$ mais caro por um MDF de baixa emissão de uréia-formol, por exemplo." Lá na Europa já exige isso. Não se entra no mercado europeu com alta emissão de uréiaformol. Então têm características diferentes para o mercado. Então, para o mercado internacional, existe esse tipo de exigência. Se a gente não se adequar, você não vende. Só que isso já tem 14 anos que nós estamos trabalhando nisso".

E atender às novas exigências do mercado nacional. Segundo o Sr. José:

Revista de Administração e Inovação, São Paulo, v. 10, n.2, p. 144-168, abr./jun. 2013. 
"O crescimento do mercado moveleiro no Brasil, e boa parte dessas madeiras vão para o mercado moveleiro, senão a grande maioria dá preferência. Por quê? $O$ consumidor hoje passa a exigir um manejo sustentável de floresta. Passa a exigir se o produto que ele está consumindo tem alguma origem de mão de obra informal, mão de obra infantil, manejo inadequado, agressão ao meio ambiente e assim por diante. Então já tem hoje moveleiros que usam isso como argumento de venda. Portanto, na cadeia dele, tem que privilegiar fornecedores que são dessa forma".

Em junho/2008, foi criado o Comitê de Sustentabilidade Ambiental, Social e Cultural da Duratex, que visa assessorar os órgãos da administração da sociedade em todos os aspectos relacionados ao desenvolvimento sustentável da sociedade, propor políticas de operação, gestão, responsabilidade socioambiental e cultural, e também, aprovar o regimento de funcionamento. Foram criados mais seis comitês internos, são eles: Inteligência Corporativa, Riscos e Ética, Governança Corporativa, Gestão de Talentos, Excelência Operacional e Excelência Comercial. Os comitês têm a participação de executivos das empresas industriais do Grupo Itaúsa (Duratex, Itautec e Elekeiroz). O objetivo é difundir as melhores práticas adotadas, promover sinergias, reduzir custos e gerar valor aos acionistas.

A Duratex coloca a gestão ambiental como parte de seu programa de qualidade e, desse modo, realiza investimentos visando à melhoria das condições de produção em paralelo com alto grau de sustentabilidade ambiental. A preocupação com a preservação das áreas ambientais é natural e necessária, pois a matéria prima de seu maior negócio, Divisão Madeira, depende da continuidade de florestas, como demonstrado na estrutura da cadeia produtiva de madeira, na Figura 1 e confirmado por Sr. José, quando esclarece:

"eu acho que essa é a base da cadeia produtiva da Duratex. A Vivência Ambiental Piatan ${ }^{l}$ que é um projeto ambiental muito bacana, fica próximo à fábrica de Agudos. Nosso viveiro fica em Lençóis, mas Agudos tem a fábrica, com 15 quilômetros, em média, dentro da mata. Há também, uma área de Vivência Ambiental, onde, todos os anos, em torno de sete mil pessoas a visitam."

\footnotetext{
1 AVAP - Área de Vivência Ambiental Piatan - Duratex - ver em http://www.duratex.com.br/Sustentabilidade/pt/Sociedade/Educacao_Ambiental.aspx; acessado em 16/06/2013.
}

Revista de Administração e Inovação, São Paulo, v. 10, n.2, p.144-168, abr./jun. 2013. 
Figura 1: Estrutura da cadeia produtiva da madeira

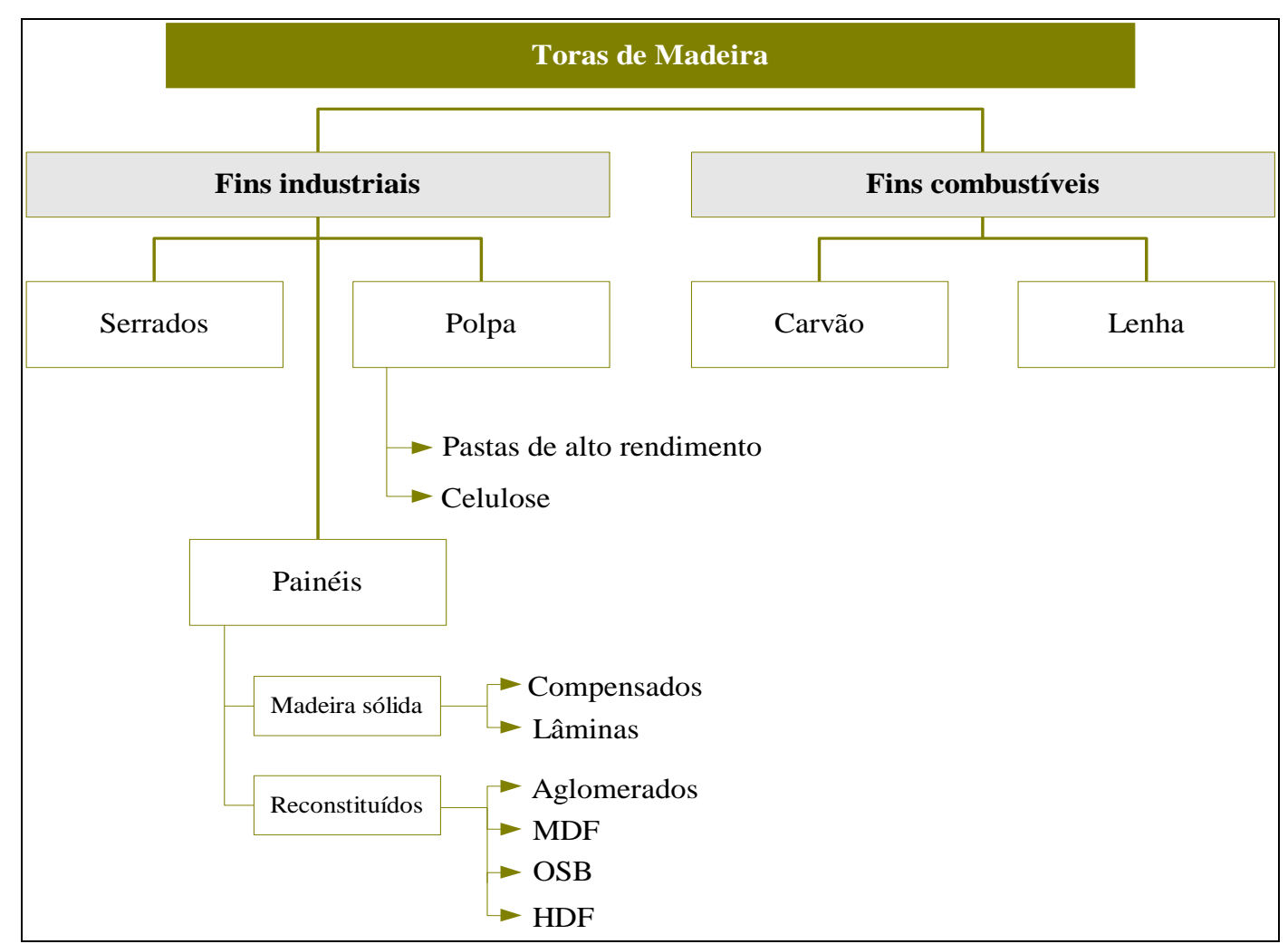

Fonte: Brasil. Ministério da Agricultura, Pecuária e Abastecimento (2007).

Contudo, a Duratex também desenvolve programas na área social com enfoque interno e externo à organização. Os programas internos têm como objetivo principal o aculturamento de seus funcionários em práticas de coleta seletiva e reciclagem de lixo, estímulo ao voluntariado social e outros.

Os programas externos têm como objetivo principal estabelecer elos de comunicação com a sociedade e stakeholders (ver Anexo A). De uma forma geral os projetos são prática de inclusão social e apoio a projetos culturais, esportivos e sociais. A seguir os principais programas: Escola de Marcenaria Tide Setúbal - em Agudos (SP), Buscando o Futuro, Projeto Bem-Querer, Área de Vivência Ambiental Piatan (AVAP) - em Agudos (SP), Projeto Educação para um Futuro Melhor, 5S e outros.

A diretriz que norteia a atuação da Duratex é a criação de valor dentro dos mais estreitos princípios de sustentabilidade. Para isso, a empresa planeja suas decisões e investimentos com base em projeções e orienta lançamentos de produtos, a partir de tendências de mercado e demanda dos 
clientes. Seu principal diferencial, em inovação, é a criação de produtos para atender a demanda do mercado, sempre a partir de pesquisas; o que representa uns dos diferenciais da empresa. As práticas sustentáveis da divisão madeira - Durafloor e da divisão Deca, são relacionadas a seguir, para identificar as inovações orientadas às políticas de desenvolvimento sustentável, objetivo específico deste trabalho.

\subsection{Divisão Madeira: Área Florestal}

Essa é a divisão da Duratex que é responsável pela fabricação de painéis de madeira feitos a partir de pinus e eucalipto, amplamente utilizados na fabricação de móveis. Dentre a linha de painéis fabricados, encontra-se a chapa de fibra, MDP (painéis de média densidade particulados), painéis de MDF, HDF e SDF (painéis de média, alta e super densidade de fibra), pisos laminados Durafloor, componentes semiacabados para móveis e uma unidade de produção de resinas industriais

No processo produtivo industrial dos painéis MDF, como apresenta a Figura 2, os recursos chave deste processo que são: árvores - eucaliptos principalmente; água e energia. O entrevistado esclarece:

"A exploração do eucalipto com a fibra, te dá essa vantagem. Então você fragmenta o eucalipto, ele vira um colchão de celulose e depois ele passa por um processo de aquecimento. Acrescenta água, tira água, acrescenta água, tira água, prensa, prensa, prensa. No final ele gera, então, um painel de alta, de média ou de baixa densidade”.

Figura 2: Cadeia de produção $M D F$

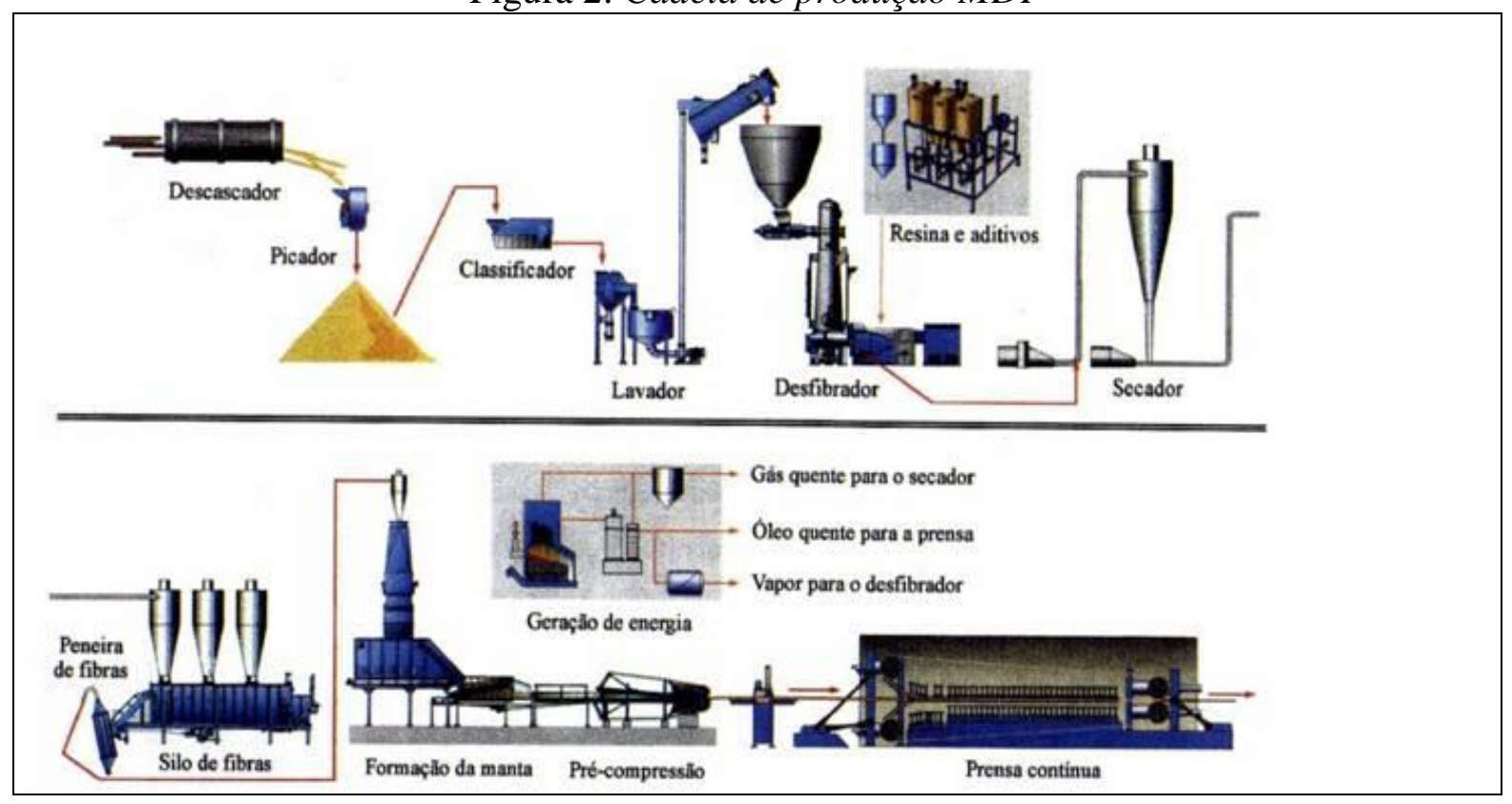

Revista de Administração e Inovação, São Paulo, v. 10, n.2, p.144-168, abr./jun. 2013. 
Fonte: Campos e Lahr (2004, p. 23).

Em 1995, a Duratex foi primeira empresa da América Latina a conquistar a certificação FSC, comprovando seu comprometimento com as questões ambientais e conservação dos recursos. A empresa conta com o reconhecimento internacional do Selo Verde, concedido pelo rigoroso Forest Stewardship Council (FSC), e da Certificação ISO 14.001, concedida pelo Bureau Veritas Quality International (BVQI). As certificações, destacadas no Quadro 1, atestam que não apenas o manejo florestal, mas toda a cadeia industrial da madeira obedece as mais exigentes normas de conservação do meio ambiente, além de permitir a sustentabilidade da operação.

Quadro 1: Certificações Duratex

\begin{tabular}{|c|c|c|l|}
\hline \hline Certificação & Outorgante & Escopo & Motivo da Certificação \\
\hline $\begin{array}{c}\text { FSC (Forest } \\
\text { Stewardship } \\
\text { Council) }\end{array}$ & $\begin{array}{c}\text { SCS } \\
\text { (Scientific } \\
\text { Certification } \\
\text { Systems })\end{array}$ & $\begin{array}{c}\text { Manejo } \\
\text { Florestal }\end{array}$ & $\begin{array}{l}\text { Atendimento aos Princípios e Critérios do FSC para } \\
\text { o bom manejo florestal (economicamente viável, } \\
\text { ambientalmente adequado e socialmente justo). }\end{array}$ \\
\hline $\begin{array}{c}\text { FSC (Forest } \\
\text { Stewardship } \\
\text { Council) }\end{array}$ & $\begin{array}{c}\text { SCS } \\
\text { Certificatific } \\
\text { Systems })\end{array}$ & $\begin{array}{c}\text { Cadeia de } \\
\text { Custódia } \\
\text { (COC) }\end{array}$ & $\begin{array}{l}\text { As chapas de madeira produzidas nas fábricas de } \\
\text { Agudos, Botucatu e Itapetininga, e aquelas } \\
\text { beneficiadas, pintadas ou expedidas da Fábrica de } \\
\text { Jundiaí, são produzidas com madeira de florestas } \\
\text { certificadas pelo atendimento aos Princípios e } \\
\text { Critérios do FSC para o bom manejo florestal. }\end{array}$ \\
\hline ISO 14001 & BVQI & $\begin{array}{l}\text { SGA existência de um Sistema de Gestão Ambiental, } \\
\text { implantado em fazendas da Unidade de Botucatu e } \\
\text { no viveiro de produção de mudas em Lençóis } \\
\text { Paulista, que atende aos requisitos da Norma NBR } \\
\text { ISO 14001. }\end{array}$ \\
\hline \hline
\end{tabular}

Fonte: Relatórios Anuais (Duratex, 2007; 2010).

A Duratex possui cerca de 110 mil hectares de florestas próprias de pinus e eucalipto, cultivadas no estado de São Paulo, o que lhe assegura a autossuficiência no suprimento da matéria prima utilizada no processo de produção, assim como a qualidade, manejo renovável e sustentável das plantações. As reservas de Lençóis Paulista, Botucatu, Itapetininga e Agudos (SP) detêm o Selo Verde concedido pela Forest Stewardship Council (FSC), organização internacionalmente reconhecida, que atesta o manejo florestal de acordo com os princípios de preservação e sustentabilidade. Há também, viveiro de produção de mudas certificados com a norma ambiental ISO 14.001 (Duratex, 2008).

$\mathrm{O}$ desenvolvimento de novas técnicas, as constantes pesquisas - a Empresa destina $\mathrm{R} \$ 1,5$ milhão ao ano ao projeto de melhoramento genético (Duratex, 2007) - e outras ações de aprimoramento ao longo da existência da área florestal permitiram aumento de produtividade superior 
a $160 \%$ (referente ao ano de 2006), representando ganho para os acionistas e sustentação para o negócio da empresa. Na área florestal, as principais melhorias no processo: A prática de cultivo mínimo, executada há 11 anos, que utiliza resíduos dos cortes anteriores para as novas plantações. Assim, os restos orgânicos protegem o solo, que tem sua capacidade potencializada também por ser pouco revolvido, o que permite o lento e contínuo acesso aos nutrientes por meio da manta orgânica em reciclagem.

O uso de adubos e de agrotóxicos é definido por controles e seleções restritos. As análises do solo e das necessidades do eucalipto definem o melhor adubo que, em vez de ser espargido, é aplicado na muda, com ganhos ambientais e de racionalização no uso do produto. Existe um constante monitoramento das florestas por técnicos em nutrição e proteção florestal o que possibilita diagnóstico e ações eficientes. O Manejo Integrado de Pragas adota uma série de medidas para garantir a produtividade das florestas e a conservação do meio ambiente. Começa com o melhoramento genético, que privilegia as árvores mais resistentes, e passa pela preservação da mata nativa, que abriga os inimigos naturais das pragas. Quando o uso de agrotóxicos é inevitável, são escolhidos os produtos de menor toxicidade, de acordo com as normas de segurança ambiental e de proteção humana, seguidos pela organização.

A empresa tem domínio de técnicas de clonagem de mudas e o envolvimento da Empresa no Projeto Genoma do Eucalipto espelha a preocupação da empresa em ganhar eficiência florestal de forma a reduzir o impacto de sua atividade no meio ambiente. Durante os últimos anos a Duratex realizou importantes investimentos voltados à expansão de sua capacidade produtiva. Foram construídas duas novas plantas: uma de painéis de aglomerados, em Itapetininga, e outra de painéis de MDF, HDF e SDF, em Botucatu, ambas no Estado de São Paulo. Juntamente com tais expansões, foram executados investimentos voltados à ampliação da capacidade de revestimento dos painéis, com o objetivo de enriquecer o mix de venda e melhorar a rentabilidade da área.

\subsection{Divisão Deca: Louças e Metais}

No âmbito industrial, foram realizados importantes investimentos relativos ao meio ambiente, como a construção de estações de tratamento de efluentes, mais tarde transformadas em áreas de reutilização de materiais, e a aquisição de filtros e lavadores de gases, além da estrita observância das normas legais. A partir de 2004, as Estações de Tratamento de Efluentes (ETEs) passaram a receber investimentos adicionais, permitindo evoluí-las para o conceito de Áreas de Recuperação de Materiais 
(ARMs). Assim, os efluentes anteriormente tratados e retornados ao sistema público, passaram a ser reaproveitados nos processos produtivos e para a manutenção das plantas. As emissões atmosféricas são reduzidas em função da instalação de filtros e lavadores de gases nas unidades. A Empresa também investiu na substituição de fornos a óleo por outros de gás natural, com menos emissão de gases.

Resíduos sólidos também recebem especial atenção, pois alguns podem ser reprocessados e reutilizados nos próprios processos, gerando ganhos operacionais por conta da redução do consumo de matéria-prima. Os resíduos metálicos são refundidos e a sucata de madeira é utilizada como biomassa para a geração de calor nas plantas. Os resíduos também são vendidos, como é o caso do hidróxido de níquel, aproveitado na indústria química, e do lodo galvânico, utilizado na indústria de fertilizantes. Os materiais descartáveis são classificados e destinados a aterros sanitários adequados.

A Divisão obteve o Prêmio FIESP de Conservação e Reúso de Água (Federação das Indústrias do Estado de São Paulo), na categoria "Médias e Grandes Empresas", participando com o case da Área de Recuperação de Materiais (ARM), que além dos benefícios de recuperação e reúso de água, permitiu reutilizar rejeitos sólidos como matéria-prima.

Nessa mesma linha, a Duratex desenvolveu uma série de produtos para racionalizar o uso da água, como torneiras, válvulas de descarga, mictórios e vasos sanitários, utilizados em locais de grande fluxo de pessoas, como hospitais, shopping centers, escritórios e hotéis. Entre os produtos dessa linha, está a Decalux. Com sistema elétrico ou bateria, e sendo acionada automaticamente por sensor, essa linha oferece potencial de economia de até $75 \%$ para torneiras e $80 \%$ para válvulas de mictório, em relação aos produtos convencionais. Outras duas linhas economizadoras são a Decamatic e a Decamatic Eco, ambas com capacidade de redução de consumo de 55\%, nos casos das torneiras, e de $80 \%$, no caso de mictórios. A empresa desenvolveu, também, controladores de vazão de água, contribuindo com até $60 \%$ de economia em torneiras e até $80 \%$ em chuveiros.

Destacam-se os investimentos realizados na Deca, com o objetivo da expansão de capacidade e a atualização tecnológica. Na área de metais sanitários, o destaque é a automação da fundição e do processo produtivo da válvula Hydra. Em louças, houve a substituição de fornos a óleo por outros mais modernos a gás, além da aquisição de equipamentos de fundição em alta pressão, de alta produtividade. Dentre os destaques para inovação em produto, encontram-se os economizadores de água, como a válvula Duo, a torneira para cozinha Fast e outros produtos voltados aos segmentos de consumos. 


\subsection{A Duratex, as Inovações Sustentáveis e Competitividade}

Os resultados da pesquisa apontam que a Duratex incorporou as diretrizes voltadas ao desenvolvimento sustentável, por intermédio de inovações de produtos e inovações de processos internos, tanto na área industrial e produtiva como nas áreas de apoio e administrativas. No Quadro 2, é apresentado um resumo de inovações orientadas ao Desenvolvimento Sustentável praticadas pela Duratex - Divisões Madeira, Louça, relatadas pelo Gerente de Sustentabilidade, Sr. José.

Quadro 2: Inovações orientadas ao Desenvolvimento Sustentável praticadas pela Duratex

\begin{tabular}{|c|c|}
\hline \multicolumn{2}{|c|}{ Divisão Madeira - Unidades Florestal e Indústria } \\
\hline $\begin{array}{l}\text { Inovação } \\
\text { Produto }\end{array}$ & $\begin{array}{l}\text { (1) MDF - MaDeFIbra Desing - Painel livre de resina uréia formol, para reunião de } \\
\text { fibras na fabricação de chapas de madeira; } \\
\text { (2) Certificação FSC ao manejo florestal. }\end{array}$ \\
\hline $\begin{array}{l}\text { Inovação } \\
\text { Processo }\end{array}$ & $\begin{array}{l}\text { (1) Eliminação do composto uréia formol; } \\
\text { (2) tratamento e reutilização de efluentes; } \\
\text { (3) destinação de resíduos sólidos e redução de emissões atmosféricas; } \\
\text { (4) áreas de recuperação de materiais; } \\
\text { (5) operação da linha de processo a seco; } \\
\text { (6) redução para } 3 \text { metros cúbicos de água por metro cúbico de produto. }\end{array}$ \\
\hline \multicolumn{2}{|c|}{ Divisão Deca - Metais e Louças } \\
\hline $\begin{array}{l}\text { Inovação } \\
\text { Produto }\end{array}$ & $\begin{array}{l}\text { (1) Torneira para cozinha Fast, Decamatic, Decamatic Eco e a válvula Duo; } \\
\text { (2) restritores de vazão de água, contribuindo com até } 60 \% \text { de economia em } \\
\text { torneiras e até } 80 \% \text { em chuveiros; } \\
\text { (3) Decalux, oferece potencial de economia de até } 75 \% \text { para torneiras e } 80 \% \text { para } \\
\text { válvulas de mictório. }\end{array}$ \\
\hline $\begin{array}{l}\text { Inovação } \\
\text { Processo }\end{array}$ & $\begin{array}{l}\text { (1) Redução do uso da água (54,5 litros por peça e louça); } \\
\text { (2) Reaproveitamento de água da chuva; } \\
\text { (3) redução do consumo de energia para } 992 \mathrm{kw} \text { por peça; } \\
\text { (4) reutilização de materiais; reciclagem de resíduos; }\end{array}$ \\
\hline \multicolumn{2}{|c|}{ Divisão Madeira e Louças } \\
\hline $\begin{array}{l}\text { Inovação } \\
\text { Gestão } \\
\text { Interna }\end{array}$ & $\begin{array}{l}\text { (1) Criação do Comitê de Sustentabilidade Ambiental, Social e Cultural da Duratex } \\
\text { S.A para tratar do tema de forma estratégica; } \\
\text { (2) Criação dos } 11 \text { Núcleos de Sustentabilidades nas fabricas; } \\
\text { (3) Incorporação de Políticas Ambientais Corporativas; } \\
\text { (4) Programa Metas Ambientais; } \\
\text { (5) Programa "Educação para a Sustentabilidade" (consumo consciente, coleta } \\
\text { seletiva, etc); } \\
\text { (6) Criação de Indicadores Ambientais. }\end{array}$ \\
\hline
\end{tabular}

Fonte: Autores (2011), com base nos Relatórios Anuais (Duratex, 2007; 2010).

A gestão ambiental faz parte do programa de qualidade da Duratex. Os investimentos no setor, que visam melhorar as condições de produção e manter a sustentabilidade ambiental, asseguram as 
certificações das florestas. Os recursos também são destinados a aquisições de filtros e construções de estações de tratamento de efluentes e de áreas de recuperação de materiais. A Empresa não apenas conserva suas próprias áreas, como promove programas de conscientização de funcionários e do público externo.

Uma gestão sustentável traz ganhos para a empresa não só no sentido competitivo de mercado, mas na redução de consumo de gastos com insumos, como o exemplo da utilização da água, recursos necessários em abundancia tanto do processo da madeira como no processo de louças e metais. Para o uso racional da água, são várias as iniciativas direcionadas à economia no consumo de água que, em 2007, totalizou 4,8 milhões metros cúbicos. Esse volume é proveniente de sistemas públicos de abastecimento (4\%), poços artesianos $(14 \%)$ e rios $(82 \%)$. A retirada tanto de poços profundos artesianos quanto de recursos de corpos d'água obedece às exigências de órgãos ambientais e não representa volume significativo em relação à vazão anual dessas fontes. Em 2007, a Empresa reutilizou em suas operações 35\% da água consumida e reciclou 4\% (Duratex, 2007).

O cuidado com o meio ambiente são preocupações centrais da Duratex, o que a leva a investir em tecnologias para reduzir o consumo de energia, aprimorar o índice de reaproveitamento de materiais e produzir o máximo com o mínimo de recursos, como pode ser comparado na Tabela 1.

Tabela 1: Total de investimentos e gastos em proteção ambiental (em $R \$$ mil).

\begin{tabular}{|l|c|c|c|c|c|}
\hline \multicolumn{7}{|c|}{ Total de investimento e gastos em protec̃ão ambiental em R\$ mil } & $\mathbf{2 0 0 8}$ & $\mathbf{2 0 0 9}$ & Variação \\
\hline & $\mathbf{2 0 0 6}$ & $\mathbf{2 0 0 7}$ & $\mathbf{2 0 0 8}$ & $-37 \%$ \\
\hline Tratamento de efluentes & 6.204 & 8.398 & 7.313 & 4.637 & $-37 \%$ \\
\hline Coleta de resíduos & 1.652 & 1.647 & 2.136 & 2.509 & $18 \%$ \\
\hline Preservação florestal & 1.025 & 1.280 & 1.301 & 1.433 & $10 \%$ \\
\hline Outros & 1.366 & 1.366 & 1.576 & 2.007 & $27 \%$ \\
\hline Total & $\mathbf{1 0 . 2 4 7}$ & $\mathbf{1 0 . 2 4 7}$ & $\mathbf{1 2 . 3 2 7}$ & $\mathbf{1 0 . 5 8 6}$ & $\mathbf{- 1 4 \%}$ \\
\hline
\end{tabular}

Fonte: Relatório Anual de Sustentabilidade (Duratex_RAS, 2009, p. 79).

A Empresa investiu, em 2010, R \$ 17,6 milhões em ações, projetos e equipamentos para a proteção ambiental, sendo destaques $\mathrm{R}$ \$ 5,6 milhões no tratamento de efluentes; $\mathrm{R}$ \$ 5,0 milhões na coleta de resíduos; $\mathrm{R}$ \$ 2,6 milhões em preservação florestal, $\mathrm{R}$ \$ 1,9 milhão em ações ambientais, $\mathrm{R}$ \$ 1 milhão em tratamento de água e R \$ 1,4 milhão em sistemas de exaustão. Adicionalmente, além desses valores, mais R\$ 1 milhão foi provisionado para a execução da remediação ambiental no site de Jundiaí, em função da desativação de uma das unidades da madeira naquela localidade.

Revista de Administração e Inovação, São Paulo, v. 10, n.2, p. 144-168, abr./jun. 2013. 
A empresa empenhou-se em proteger o meio ambiente, criando a Reserva Natural Olavo Egydio Setúbal, uma área de 600 hectares em sua unidade de Lençóis Paulista (SP).

Em 2007, a empresa deu inicio ao processo de adesão à Chicago Climate Exchange, bolsa de comercialização de créditos por sequestro de carbono, fato que, além de atestar a empresa como neutralizadora de todas as suas emissões de gases, o que eleva à organização ao status de Carbon Free, a empresa ainda conta com um excedente que poderá ser negociado na bolsa. Veja estoque de $\mathrm{CO}_{2}$ da Duratex em 2010 na Tabela 2.

Tabela 2: Estoque de $\mathrm{CO}_{2}$ Duratex.

\begin{tabular}{|l|c|c|c|c|}
\hline $\begin{array}{l}\text { Projeto Carbono - Estoque de } \mathrm{CO}_{2} \text { na } \\
\text { Floresta Plantada }\end{array}$ & 2007 & 2008 & 2009 & 2010 \\
\hline Área Própria Total no Projeto (hectares) & $56.799,09$ & $58.801,84$ & $60.940,42$ & $61.067,51$ \\
\hline Volume Total de Toneladas de $\mathrm{CO}_{2}$ & $5.609,74$ & $803.794,65$ & $1.325 .394,80$ & $924.714,93$ \\
\hline $\begin{array}{l}\text { (1) A área de efetivo plantio totalizou 136,2 mil ha. em 2010. Portanto, o estoque de } \mathrm{CO}_{2} \text { apontado no } \\
\text { Projeto é conservador. }\end{array}$
\end{tabular}

Fonte: Relatório Anual de Sustentabilidade (Duratex_RAS, 2010, p. 47).

Na Bolsa de Valores de São Paulo o desempenho da empresa foi reconhecido pela inclusão das ações da empresa no Ibovespa, índice que reúne as principais ações negociadas no mercado, também classificada no ISE - Índice de Sustentabilidade Empresarial da Bovespa. A Duratex, também teve suas ações incluídas em outro importante índice de mercado, o IbrX50, cuja carteira compreende as 50 ações mais líquidas negociadas em bolsas de valores. As ações da Duratex, ao longo do ano do estudo, tiveram como reconhecimento do mercado, os prêmios listado no Quadro 3.

Quadro 3: Prêmios recebidos pela Duratex em 2007.

\begin{tabular}{|c|c|}
\hline \hline \multirow{2}{*}{ Divisão Madeira } & $\begin{array}{c}\text { Prêmio Pini (pela 6 }{ }^{\mathrm{a}} \text { vez consecutiva) } \\
\text { Top Marcas (pela } 3^{\mathrm{a}} \text { vez consecutiva) }\end{array}$ \\
& $\begin{array}{c}\text { Prêmio da Excelência Empresarial (promovido pelo } \\
\text { Instituto Brasileiro de Economia - Ibre) }\end{array}$ \\
\hline Divisão Deca & iF Product Desing Award \\
& $16^{\mathbf{o}}$ Prêmio Anamaco (três categorias - Metais \\
& Sanitários Economizadores, Metais Sanitários e \\
& Sistemas de Descargas) \\
Mercado Desing - Top 21
\end{tabular}

Fonte: Autores (2011) baseados nos Relatórios Anuais (Duratex, 2007; 2010). 


\section{CONSIDERAÇÕES FINAIS}

O presente artigo originou-se de uma pesquisa, que teve como objetivo identificar se as inovações orientadas por políticas de desenvolvimento sustentável influenciavam na competitividade da empresa estudada, de modo a revelar-se, um fator de competitividade. Por meio dos resultados obtidos foi possível apresentar as seguintes considerações.

A empresa em 2007 teve desempenho recorde (lucro líquido evoluiu 41\%, referente a 2006), que se deveu a fatores macroeconômicos e, principalmente, a ações estratégicas adotadas pela empresa ao longo de sua trajetória. No mesmo período, foi criado o Comitê de Sustentabilidade Social, Ambiental e Cultural e, também, o Comitê de Negociação e Divulgação de Ato e Fato Relevante. Antes que a Duratex inserisse políticas de desenvolvimento sustentável formalmente em sua gestão, a empresa já adotava práticas sustentáveis de manejo florestal, provavelmente por ser o início de sua cadeia produtiva e atividade estratégica. Desde cedo, a empresa percebeu que a tendência do mercado, principalmente externo, seria a valorização de produtos e processos de fabricação éticos, respeitando o equilíbrio entre meio ambiente, sociedade e economia.

Interessada em uma cadeia de valores sustentável que proporcione à empresa posição competitiva em longo prazo, a empresa está convicta que "há uma restrição de recursos naturais não renováveis", onde "os desperdícios dessas matérias-primas devem ser coibidos". A empresa acredita que as pessoas não vão deixar de consumir, mas irão selecionar o que consomem. A consistência na gestão corporativa diminui o risco ambiental e consequentemente diminui o risco geral de investidores e da empresa. O valor de mercado da empresa tem crescido significativamente, demonstrando que inovações de produtos e processos orientadas às práticas de desenvolvimento sustentável acarretam em melhor posição competitiva. A relação entre Receita Líquida e Margem Bruta cresceu 17,9\% no período de 2007 a 2008, mostrando que as práticas de DS podem ser uma oportunidade de negócio.

Os resultados que podem ser observado no estudo, mostram que a Duratex empenhou-se em adaptar seus produtos e processos às condições impostas pelo mercado de vanguarda, tais como, a preocupação com o meio ambiente, devido à restrição dos recursos naturais, atendimento das mais exigentes leis ambientais (nacionais e internacionais), e percepção do consumidor ao que tange a ações sociais e sustentáveis.

Como conclusão deste trabalho e resposta à questão investigada, se as inovações empresariais orientadas pelas políticas de desenvolvimento sustentável influenciam na competitividade da Duratex, 
não se pode afirmar que o desempenho financeiro da Duratex ocorreu até então em função de suas políticas de sustentabilidade; entretanto, a decisão de incluir preceitos do desenvolvimento sustentável em suas escolhas estratégicas e operacionais, pode ser um fator de eficiência responsável pela sobrevivência e desempenho satisfatório daqui para frente. A partir do momento que a Duratex inseriu a sustentabilidade na cultura empresarial, a grande parte das inovações, de produtos e processos, foi orientada por suas políticas. Seguindo a classificação de inovação de adotada no estudo, pode-se dizer que as inovações realizadas pela Duratex ocorreram com a concepção de ser sustentável, como é o caso da válvula HydraDuo que regula a vazão de água de líquidos e sólidos e do piso.

Sendo assim, do ponto de vista dos fenômenos estudados: "inovação orientada ao DS" e "competitividade da Duratex", conclui-se que a empresa tem uma relação positiva principalmente no que diz respeito ao posicionamento futuro da empresa em seu setor de atuação. O que se observa hoje é consequência de uma gestão eficiente e ética, onde mesmo não sendo utilizado o termo “desenvolvimento sustentável”, a trajetória da Duratex se mostrou preocupada em preservar e desenvolver recursos com visão de longo prazo, que pudesse sustentá-la no mercado.

\section{REFERÊNCIAS}

Ayuso, S., Angel, M., Ricart, R. \& Ricartr, J.E. (2006). Responsible competitiveness at the "micro" level of the firm using stakeholder dialogue as a source for new ideas: a dynamic capability underlying sustainable innovation. Corporate Governance. Vol. 6 No. 4. 2006, pp. 475-490, Q Emerald Group Publishing Limited.

Bossink, B. A.G. (2007). Leadership for sustainable innovation. International Journal of Technology Management and Sustainable Development. Vol.6 N. 2 (c) 2007 Intellect Ltd.

BOVESPA, Bolsa de Valores do Estado de São Paulo. (2007). Recuperado em 04 de agosto, 2007, de http://www.bovespa.com.br/Principal.asp.

Brasil. Ministério da Agricultura, Pecuária e Abastecimento. (2007). Cadeia produtiva de madeira. Ministério da Agricultura, Pecuária e Abastecimento, Secretaria de Política Agrícola, Instituto Interamericano de Cooperação para a Agricultura; coordenadores Antonio Márcio Buainain e Mário Otávio Batalha. - Brasília: IICA: MAPA/ SPA, v. 6.

Brito, L. A. L. \& Vasconcelos, F. C. (2004). Vantagem competitiva: o construto e a métrica. RAE Revista de Administração de Empresas, 44(2), 51-63.

Bryman, A. (2004). Social research methods. $2^{\mathrm{a}}$ ed. London: Oxford University Press.

Revista de Administração e Inovação, São Paulo, v. 10, n.2, p.144-168, abr./jun. 2013. 
Bruntland (1987). Report of the World Commission on Environment and Development: Our Common Future. Recuperado em 02 de setembro de 2011, de http://www.un-documents.net/wced-ocf.htm.

Campos, C. I. \& Lahr, F. A. R. (2004). Estudo Comparativo dos Resultados de Ensaio de Tração Perpendicular para MDF Produzido em Laboratório com Fibras de Pinus e de Eucalipto Utilizando Uréia-Formaldeído.Matéria. Vol. 9, № 1 (2004) 32 - 42. Recuperado em 14 de fevereiro, 2009, de http://www.materia.coppe.ufrj.br/sarra/artigos/artigo10592.

CEBDS. Centro Brasileiro para o Desenvolvimento Sustentável. (2007). Recuperado em 19 de novembro, 2007, de http://www.cebds.org.br/cebds/Noticias.asp?ID=207\&bc=1.

CLACDS. Centro Latino-Americano para Competitividade e Desenvolvimento Sustentável (2007). Recuperado em 10 de setembro, 2007, de http://www.incae.ac.cr/ES/clacds.

Creswell, J. W. (1998). Qualitative inquiry and research design: choosing among fives traditions. London, UK.: Sage Publications.

Dosi, G. (2006). Mudança técnica e transformação industrial: a teoria e uma aplicação à indústria dos semicondutores. São Paulo: Editora da UNICAMP, 460 p.

Duratex. (2007; 2009; 2010). Recuperado em novembro, 2007 a fevereiro, 2009, de www.duratex.com.br.

Eisenhardt, K. M. (1989). Building theories from case study research. The Academy of Management Review, vol. 14, nº. 4, p. 532-550, Oct.

Ethos, Instituto. (2007). Recuperado em 20 de outubro, 2007, de www.ethos.org.br.

FBDS (2011). Fundação Brasileira para o Desenvolvimento Sustentável. Recuperado em 18 de agosto de 2011, de http://fbds.org.br.

Ferraz, J.C., Kupfer, D. \& Haguenauer, L. (1996). Made in Brazil. RJ: Editora Campus.

Flores, J.G. (1994) Aproximación interpretativa al contenido de la información textual. In: Análisis de datos cualitativos: aplicaciones a la investigación educativa. Barcelona: PPU, p. 65-107.

Godoy, A. S. Estudo de caso qualitativo. (2006). In: Silva, A. B. da; Godoi, C. K.; Bandeira-de-Mello, R. Pesquisa qualitativa em estudos organizacionais: paradigmas, estratégias e métodos. São Paulo: Saraiva, p. 115-146.

GVCES. Centro de Estudos de Sustentabilidade Fundação Getúlio Vargas. (2007). Recuperado em 15 de novembro, 2007, de http://ces.fgvsp.br/.

Haguenauer, L. (1989). Competitividade: conceitos e medidas. Rio de Janeiro: UFRJ/IEL. Recuperado em 10/10/2012 de http://www.ie.ufrj.br/gic/pdfs/1989-1_Haguenauer.pdf.

Hall, J. \& Vredenburg, H. (2003). 'The challenges of innovating for sustainable development', MIT Sloan Management Review, Vol. 45 No. 1, pp. 61-8.

Revista de Administração e Inovação, São Paulo, v. 10, n.2, p. 144-168, abr./jun. 2013. 
Hart, S.L. \& Milstein, M.B. (1999). 'Global sustainability and the creative destruction of industries'” Sloan Management Review, Vol. 41 No. 1, pp. 23-33.

Hughes, A. (1987). "managerial capitalism". The New Palgrave: A Dictionary of Economics, v. 3, pp. 293-96.

INCAE. (2011). Recuperado em 10 de agosto de 2011, de http://www.incae.edu/es/clacds/.

Kupfer, D. (1992). Padrões de Concorrência e Competitividade, 1992. Versão revisada do texto 265, IEI/UFRJ, Anais do XX Encontro Nacional da ANPEC, Campos de Jordão, SP.

Romeiro, A. R. (2001). Economia ou economia política da sustentabilidade? Texto para Discussão. IE/UNICAMP, Campinas, n. 102, set. 2001. Recuperado em 29 de maio, 2006, de www.unicamp.br.

Sambiase-Lombardi, M.F \& Brito, E.Z.P. (2007). Desenvolvimento sustentável como fator de competitividade [CD-ROM]. Anais do Encontro da Associação Nacional de Pós-Graduação $e$ Pesquisa em Administração, ENANPAD, Rio de Janeiro.

Sbragia, R., Stal, E, Campanário, M.A. \& Andreassi, T. (2006). Inovação. Editora Clio.

Schaltegger, S. \& Wagner, M. (2008). Types of sustainable entrepreneurship and conditions for sustainability innovation: from the administration of a technical challenge to the management of an entrepreneurial opportunity, UK: Edward Elgar. In: Wüstenhagen, Rolf; Hamschmidt, Jost, Sharma, Sanjay \& Starik, Mark. Sustainable innovation and entrepreneurship. Cheltenham. UK: Edward Elgar, p. 27-48.

Schumpeter, J. A. (1961). The Theory of Economic Development. An Inquiry into Profits Capital Credit, Interest, and the Business Cycle. New York: Oxford University Press.

Senge, P.M., Carstedt, G. \& Porter, P. (2001). Innovating Our Way to the Next Industrial Revolution. MIT Sloan Management Review; Winter 2001; ABI/INFORM Global pg. 24.

Tidd, J., Bessant, J, R. \& Pavitt, K. (2008). Gestão da Inovação. 3a. ed. Porto Alegre: Bookman.

Yin, R. K. Estudo de caso. (2003). $2^{\mathrm{a}}$ ed. Porto Alegre-RS: Bookman.

Revista de Administração e Inovação, São Paulo, v. 10, n.2, p.144-168, abr./jun. 2013. 


\section{Anexo A: Quadro de Interações com Stakeholders}

\begin{tabular}{|c|c|c|}
\hline \multicolumn{3}{|c|}{ Quadro das Interações } \\
\hline $\begin{array}{l}\text { Parte } \\
\text { Interessada }\end{array}$ & Canais de comunicação & Principais ações \\
\hline $\begin{array}{l}\text { Acionistas e } \\
\text { Investimentos }\end{array}$ & $\begin{array}{l}\text { Teleconferências trimestrais sobre os } \\
\text { resultados econômico-financeiros; rood } \\
\text { shows no Brasil e exterior; reuniões } \\
\text { individuais e em grupo e visitas de analistas } \\
\text { às fábricas; reuniões públicas com analistas } \\
\text { no Brasil, América do Norte e Europa; } \\
\text { relatório anual; canal no site para a área de } \\
\text { Relações com Investidores, com contato } \\
\text { próprio para a comunicação; alertas por e- } \\
\text { mail para a divulgação de eventos de } \\
\text { interesse; canal de relacionamento sobre o } \\
\text { tema meio ambiente. }\end{array}$ & $\begin{array}{l}\text { Divulgação, no website, de informações nos } \\
\text { âmbitos econômico-financeiro, social, } \\
\text { ambiental e cultural; relatórios trimestrais } \\
\text { contendo a discussão dos resultados } \\
\text { econômico-financeiros e desempenho social } \\
\text { e ambiental; Código de Ética e Conduta; } \\
\text { Comitê de Divulgação e Negociação; } \\
\text { Política de Negociação de Valores } \\
\text { Mobiliários; Política de Divulgação de Ato } \\
\text { ou Fato Relevante. }\end{array}$ \\
\hline $\begin{array}{l}\text { Clientes e } \\
\text { consumidores }\end{array}$ & $\begin{array}{l}\text { Serviço telefônico gratuito de atendimento } \\
\text { ao cliente; website corporativo, Deca e } \\
\text { Madeira; Revista Duratex e boletim } \\
\text { Duratex Informa; relatório anual; canal de } \\
\text { relacionamento sobre o tema meio } \\
\text { ambiente. }\end{array}$ & $\begin{array}{l}\text { Programas de treinamento Ciclo Saber é } \\
\text { Vender; serviços de atendimento ao cliente } \\
\text { e de assistência técnica; propaganda dos } \\
\text { produtos sob padrões éticos; } \\
\text { desenvolvimento de produtos ecoeficientes; } \\
\text { Comitê de Crédito; Código de Ética e } \\
\text { Conduta. }\end{array}$ \\
\hline Fornecedores & $\begin{array}{l}\text { Revista Duratex e boletim Duratex } \\
\text { Informa; website; relatório anual; canal de } \\
\text { relacionamento sobre o tema meio } \\
\text { ambiente. }\end{array}$ & $\begin{array}{l}\text { Política de fornecimento de Bens e } \\
\text { Serviços; Programa na Mão Certa; Código } \\
\text { de Ética e Conduta. }\end{array}$ \\
\hline Colaboradores & $\begin{array}{l}\text { Canais confidenciais de denúncia contra } \\
\text { discriminação no trabalho; canal de } \\
\text { relacionamento sobre o tema meio } \\
\text { ambiente; RH Escuta; quadros internos de } \\
\text { aviso; Intranet; Revista Duratex e boletim } \\
\text { Duratex Informa; website; relatório anual. }\end{array}$ & $\begin{array}{l}\text { Programas de educação e treinamento; } \\
\text { eventos em datas como dia da secretária, } \\
\text { dia das mães e final de ano; Código de } \\
\text { Ética e Conduta; Comitê de Pessoas e } \\
\text { Sucessão. }\end{array}$ \\
\hline Comunidade & $\begin{array}{l}\text { Reuniões nas comunidades; relatório anual; } \\
\text { website; canal de relacionamento sobre o } \\
\text { tema meio ambiente. }\end{array}$ & $\begin{array}{l}\text { Promoção da educação ambiental na Área } \\
\text { de Vivência Ambiental Piatan (Avap), em } \\
\text { Agudos (SP); Escola de Marcenaria Tide } \\
\text { Setúbal; Comitê de Sustentabilidade; } \\
\text { Reserva Natural Olavo Egydio Setúbal, em } \\
\text { Lençóis Paulista (SP); patrocínio a eventos } \\
\text { culturais e sociais. }\end{array}$ \\
\hline $\begin{array}{l}\text { Governo e } \\
\text { sociedade }\end{array}$ & $\begin{array}{l}\text { Relatório anual; website; canal de } \\
\text { relacionamento sobre o tema. }\end{array}$ & $\begin{array}{l}\text { Código de Ética e Conduta; Política para a } \\
\text { Recepção e tratamento de Denúncias; } \\
\text { Políticas Ambiental; adesão ao Pacto } \\
\text { Global da ONU; adesão ao Green Building } \\
\text { Council Brasil, como membro-fundador; } \\
\text { participação e contribuição em associações, } \\
\text { entidades e iniciativas sustentáveis, como o } \\
\text { Instituto Ethos e o Programa na Mão Certa; } \\
\text { certificação ISO } 14001 \text { e FSC. }\end{array}$ \\
\hline Imprensa & $\begin{array}{l}\text { Relatório anual; assessoria de imprensa; } \\
\text { website; e-mail alert. }\end{array}$ & $\begin{array}{l}\text { Código de Ética e Conduta; Comitê de } \\
\text { Negociação e Divulgação. }\end{array}$ \\
\hline
\end{tabular}

Fonte: Relatório Anual de Sustentabilidade (Duratex, 2010, p. 25). 


\title{
INNOVATION FOR SUSTAINABLE DEVELOPMENT AS A COMPETITIVE FACTOR FOR ORGANIZATIONS: A CASE STUDY DURATEX
}

\begin{abstract}
This study aimed to investigate the relationship between sustainable development and competitiveness of organizations in order to identify whether the innovations driven by corporate policies of sustainability organizational influence on the competitiveness of Duratex; Brazilian company producer of wood products, pottery and metal fittings, for the furniture industry and construction. This work consists of theoretical, explaining concepts related to the competitiveness of organizations, sustainable development and business innovation, as well as the relationships between them. The survey was an exploratory, qualitative approach through the strategy of the case study of Duratex and lifting techniques of documentary evidence, secondary, semi-structured interviews and observation. Analyses of the interviews were conducted according to the technique of textual analysis and point to results showing that Duratex entered sustainability in their strategic and operational management, having profited from innovations in products and processes in search of balance between social, ecological and economic practices distributed throughout the production chain. Thus, innovations are raised oriented toward sustainability, and business performance results indicate that not only innovative, but the management-oriented sustainability Duratex contributes to it and the company's competitive position.
\end{abstract}

Keywords: Innovation; Sustainability; Sustainable Development; Competitiveness.

Data do recebimento do artigo: 07/12/2012

Data do aceite de publicação: 15/05/2013

Revista de Administração e Inovação, São Paulo, v. 10, n.2, p.144-168, abr./jun. 2013. 